\title{
Problems of elderly health care and welfare arrangement-Case study of demand on elder care in northeastern of Thailand
}

\author{
Thitiwan Sricharoen ${ }^{1}$, Wuttipong Arjchariyaartong ${ }^{2}$ \\ (1. Faculty of Management Science, Khon Kaen University, Khon Kaen 40002, Thailand; \\ 2. Department of Economics, Khon Kaen University, Nong Khai Campus, Nong Khai 340000, Thailand)
}

\begin{abstract}
This research attempted to explain the problems of elderly health care, the problems and suggestion in elder welfare arrangement and the demand on elder care. The survey underlying this study was conducted in Muang district, Khon Kaen province, Thailand. Eighteen subdistricts were interviewed in the study area. Data were collected in two areas of Khon Kaen province, that are, the city of Khon Kaen and the outside Thesaban Nakhon Khon Kaen. The random sample consisted of 386 elders: 112 elders lived in the city of Khon Kaen and 234 elders lived outside Thesaban Nakhon Khon Kaen, Muang district, Khon Kaen. The analysis of the demand on elderly welfare gave an interesting result that the elders demanded on monthly income to support living cost and medical services at high level; The demand on housing was at low level; The demand on education, religion and culture the demand on club, sport and entertainment, and the demand on job and art were at the moderate level; The main problem of elderly welfare arrangement was the scarcity of budget support, the weakness of elder health, and activities announcement. The analysis of pattern of elder welfare: The case study of elder care identified that 31.87 percent of the elders had demand on elder care. Price of the elder care at 100 Baht per day was mostly selected about one-fourth of all the case occurred. Female elder selected the elder care at 100 Baht per day, while male elder choose at a higher price level, which were 200 Baht per day and 150 Baht per day respectively. The female elder care was the most popular. The elder care age between 30-39 years was mostly selected. Finally, most of elders purposed the working day of the elder care depend on their appointment.
\end{abstract}

Key words: elder; elderly health care; elder care; elderly welfare arrangement

\section{Introduction}

In the past, Thai society had social support and social network system. These systems play an important role in supporting the elders. Although in the past, most of the elder could not access to the elderly welfare arrangement but it did not cause any much problem. However, nowadays the economics and society has been changed, the elders must help themselves and have more significance problem.

According to Fig. 1, the statistics indicates the share of the elder in Thailand has an increased trend. The estimation of the growth of the elder shows that in the next 20 years, Thailand may be the same as Japan in the present population structure, which has the reduction share of labor force per elder (aged more than 60 years old).

Table 1 show the survey of Thailand national statistics in 1998 about the number of the elders are 5.97

\footnotetext{
Thitiwan Sricharoen, Ph.D., Faculty of Management Science, Khon Kaen University; research field: development economics.

Wuttipong Arjchariyaartong, Ph.D., Department of Economics, Khon Kaen University, Nong Khai Campus; research field: industrial economics.
} 
million persons or 9.4 percent of total population, divided in 2.73 million of male and 3.24 million of female. Most of the elder live in rural area. Considering to the share of elderly dependency ratio shows the northern of Thailand has the highest share of the elder at 11.1 percent, following by the central with 10.6 percent, the south with 8.7 percent and the northeast with 8.6 percent (National Economics and Social Advisory Council, 2007).

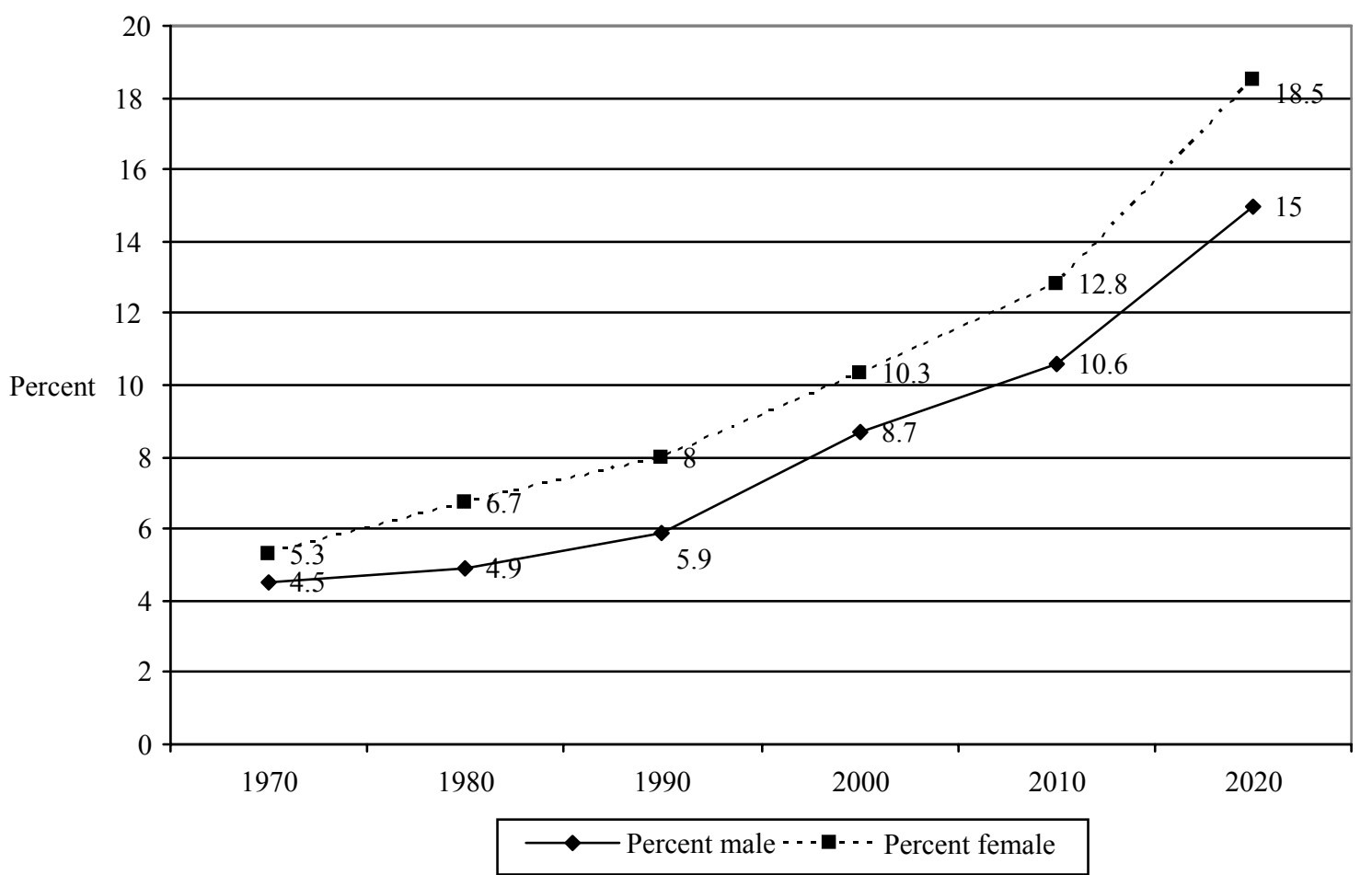

Fig. 1 Percentage of the elder classified by gender from 1970-2020

Data source: National statistics of Thailand (1970-2000); National economics and social advisory council:

The estimation of Thailand population from 2000 to 2020.

Table 1 Number and percent of the elder classify by the age of population and the region in 2002

\begin{tabular}{|c|c|c|c|c|c|c|c|c|}
\hline \multirow{2}{*}{ Age of population } & \multicolumn{3}{|c|}{ Overall country } & \multirow{2}{*}{ Bangkok } & \multicolumn{4}{|c|}{ Region } \\
\hline & Total & Municipality & $\begin{array}{c}\text { Outside } \\
\text { municipality }\end{array}$ & & Central & North & Northeast & South \\
\hline Total (thousand person) & $5,969.0$ & $1,851.9$ & $4,117.1$ & 619.4 & $1,531.7$ & $1,257.0$ & $1,824.6$ & 736.3 \\
\hline Age group & 100.0 & 100.0 & 100.0 & 100.0 & 100.0 & 100.0 & 100.0 & 100.0 \\
\hline 60-64 year & 34.7 & 35.2 & 34.5 & 36.6 & 33.3 & 32.9 & 36.4 & 35.1 \\
\hline $65-69$ year & 28.0 & 27.9 & 28.0 & 28.1 & 27.7 & 28.6 & 27.7 & 28.0 \\
\hline 70-74 year & 18.4 & 17.6 & 18.9 & 15.9 & 18.1 & 19.7 & 18.9 & 17.8 \\
\hline$>75$ year & 18.9 & 19.3 & 18.7 & 19.4 & 20.9 & 18.8 & 17.0 & 19.1 \\
\hline
\end{tabular}

Data source: National statistics of Thailand (2002).

Furthermore, the survey of the ministry of health in 2007 give the result that there are the changes in population structure, because the population of Thailand tends to have prolonged life between the population age 60 and 70. The population aged 60 years has an opportunity to have prolonged life. The changing of Thailand population structure between 1982 and 1986 compare to the year 1995 and 1996 indicate that male population age 60 years has longer life 4.8 years and female population has longer life 5.4 years. Women have average years of 
prolong life longer than men significantly (Ministry of Thailand Health, 2007). The rate of increased prolong life cause in the increased number of the elder population. If the social welfare arrangement for the old age people is not well support for them to sustain their living, the elder in Thailand livelihood may fragile and this will make the problem to society. The elder generally has no salary and is not in labor force, therefore, the arrangement of the elder welfare is important.

\section{Methodology}

This research has objective to identify the problem of the elder health care, demand on the elder welfare arrangement and the demand of the elder care. Methodology used in this study applies conjoint analysis (CA), which is multivariate technique to describe pattern of social welfare that the elders are satisfied. The basic conjoint analysis (CA) model may be represented by equation (1) (Malhotra, 2004):

$$
Y=\sum_{i=1}^{n} \sum_{j=1}^{m} \beta_{i j} X_{i j}
$$

where $Y$ denotes the elders' overall preference, respectively choice for the elder care service alternatives under investigation. These alternatives are described in terms of $j$-levels for $i$-attributes. $\beta_{i j}$ is the part-worth utility associated with the $j$ th level of the $i$ th attribute. The part-worth utility measures the relative importance of $X_{i j}$ in estimating the dependent variable. $X_{i j}$ is a control variable to flag either presence $\left(X_{i j}=1\right)$ or absence $\left(X_{i j}=1\right)$ of the $j$ th level for the $t$ th attribute.

The attribute of the elder demand on the elder care profile analyzed here are:

$Y=$ The elder care profile choice; $X=$ Explanatory the elder care concept variable; $\varepsilon=$ Error term.

$X_{i}$ for $i=1$ to $5: X_{1}=$ price; $X_{2}=$ gender of the elder care; $X_{3}=$ age of the elder care; $X_{4}=$ working date; $X_{5}=$ working choice.

The levels for each attribute are:

$X_{1 j}$ for $j=1$ to $3: X_{11}=100$ Baht per day; $X_{12}=150$ Baht per day; $X_{13}=200$ Baht per day.

$X_{2 j}$ for $j=1$ to $2: X_{21}=$ male; $X_{22}=$ female.

$X_{3 j}$ for $j=1$ to $3: X_{31}=20-29$ years old; $X_{32}=30-39$ years old; $X_{33}=$ more than 40 years old.

$X_{4 j}$ for $j=1$ to $4: X_{41}=$ Monday-Sunday; $X_{42}=$ Monday-Friday; $X_{43}=$ Saturday-Sunday; $X_{44}=$ working date and time depend on appointment.

$X_{5 j}$ for $j=1$ to $2: X_{51}=$ Come to work and lives with the elder at home; $X_{52}=$ Come to work in the morning and go back in the afternoon.

The random sampling of old age population in Muang district, Khon Kaen province, Thailand was done. There are 386 samples out of total 33,659 elders in Khon Kaen. The survey result of demand on elder welfare arrangement indicates that the elder has demand on different welfare from person to person. For example, demand on housing, elder care, medical care service, education, religion and culture, club, sport and entertainment activities, occupation, art. Demand on housing and elder care contains the highest demand.

\section{Research area}

Studies on problem of health care and pattern of elderly welfare arrangement aim at studying on problem of elderly health care and studied on demand on elderly welfare arrangement, which emphasis on the demand on the elder care. 
Scope of study concentrated on analyzing problem and pattern of elder welfare arrangement. Research area was in Muang district, Khon Kaen province, Thailand, which divided into the elder who live in Khon Kaen city or in Thesaban nakorn Khon Kaen and the elder who live outside Thesaban nakorn Khon Kaen. Population in this study are 386 elders aged above 60 years old, 112 elders lived in urban area and 234 elders live in rural area.

\section{Analysis of the results}

The analysis on the economics and problem of the elder explain that about 18.65 percent of the elder has no income. Among this group, there is gap between the elder who has low income less than 4,000 Baht per month and the others who have high income more than 20,000 Baht per month. Main sources of income come from occupation, son and relatives, government pension fund with 40,33 and 18 percent respectively. Most of elder has problem on the consistency of income per month. The elder who did not have government working experience has great problem after retirement age. Most elders have problem of unhealthy problem and the difficulties to find job. This lead them have no other income sources. Around 45.60 percent of the elder do not have enough income per month. About 37.31 percent has debt, which borrow from bank and teacher saving corporative bank. Therefore, the elder mostly encounter the risk of acquirement income to sustainable living.

In overall, the elders who live with family present an optimistic opinion that family member takes good care of them and the relationship between them are at good level. However, most of the elders have problem with sickness. About 51.81 percent of the elder have 3-4 disease per person, but they have small problem on health care cost because most of them use universal health care card. Most of them can access to the elder welfare service at the moderate level.

Result of the elder social network shows that about 24 percent of the elder participate in many different club. About 66 percent of them get in touch on news. Most of them join the social event both in formal and informal ways.

Survey on demand on elder welfare arrangement indicates that the elder has demand on money support per month at high level with 30 percent. They have demand on housing at low to lowest level due to the elder rely on family assistance. They have demand on medical care service at high level. Most of the elders have demand on the rest elder welfare arrangement, which are demand on education, entertainment activities and employment at the moderate level (see Table 2).

Table 2 Demand on elder welfare arrangement

\begin{tabular}{lccccc}
\hline \multirow{2}{*}{ Demand on elder welfare arrangement level } & \multicolumn{3}{c}{ Percent } \\
\cline { 2 - 6 } & Highest & High & Moderate & Low & Lowest \\
\hline Demand on money support & 27.46 & 30.31 & 22.54 & 10.10 & 9.59 \\
Demand on housing & 9.84 & 12.95 & 16.06 & 32.64 & 28.50 \\
Demand on medical care service & 25.13 & 43.01 & 22.80 & 4.40 & 4.66 \\
Demand on education, religion and culture activities & 11.14 & 26.42 & 44.04 & 10.36 & 8.03 \\
Demand on club, sport and entertainment & 9.59 & 19.17 & 46.37 & 15.54 & 9.33 \\
Demand on employment & 6.48 & 13.99 & 39.12 & 25.39 & 15.03 \\
\hline
\end{tabular}

Data source: the authors' calculation.

Factor affecting on the elder welfare arrangement are budget, the great number of the elder, the external aids, community size, the role of the community head and the participation of the community member respectively (see 
Table 3).

Problem and obstruction of welfare arrangement are budget, the unhealthy of the elder cause them can not participate in group and activities, problem of the activities announcement, problem of the seeking interests on the elder and problem of the internal and external corporation respectively (see Table 4).

Table 3 Factor affecting on the elder welfare arrangement

\begin{tabular}{|c|c|}
\hline Factor & Percent \\
\hline The limitation of budget & 18.80 \\
\hline The high number of the elder & 13.00 \\
\hline The external aids & 10.70 \\
\hline The community size & 9.83 \\
\hline The role of the community head & 9.63 \\
\hline The participation of member in community & 8.14 \\
\hline The integration of the elder & 7.94 \\
\hline The interesting of the activities & 7.45 \\
\hline The management of welfare arrangement & 7.25 \\
\hline The role of community administrative committee & 4.67 \\
\hline The role of saving group head & 2.58 \\
\hline Total & 100.00 \\
\hline
\end{tabular}

Data source: the authors' calculation.

Table 4 Problem and obstruction of welfare arrangement

\begin{tabular}{lc}
\hline Problem/Obstruction & Percent \\
\hline The limitation of budget supports & 26.00 \\
The weakness health of the elder cause they can not participate the activities & 15.80 \\
The announcement of activities & 8.41 \\
The seeking interests on the elder & 8.20 \\
The coordination between internal and external community & 8.00 \\
No place to arrange the activities & 7.58 \\
Not enough staff to run the activities & 7.48 \\
The elder have been force to do the activities & 5.71 \\
Financial and accounting management & 4.78 \\
Lack of harmony or unity & 4.15 \\
The limit time of committee & 3.95 \\
\hline Total & 100.00 \\
\hline
\end{tabular}

Data source: the authors' calculation.

According to the analysis of welfare arrangement in the case of elder care demand which presents that 123 elders out of 386 elders have demand on the elderly care, accounting for 31.87 percent. The price 100 Baht per day has been mostly selected, amounting for one-fourth of all case it occurred. When compare the price of elderly care by gender, female elder choose the price at 100 Baht per day more than male elder. However, at the higher price, 200 Baht per day and 150 Baht per day are the price that male elder have much more interested in. Moreover, analysis on the gender of carer present that female elderly carers are most popular. The elderly carers aged between 30 to 39 years are most selected. Working day of elderly carer that has been most choose are the 
Problems of elderly health care and welfare arrangement-Case study of demand on elder care in northeastern of Thailand

date and time flexible to the appointment (see Table 5).

Table 5 Attribute main effect and significant level of attribute of the elderly carer classified by gender

\begin{tabular}{|c|c|c|c|}
\hline \multirow{2}{*}{ Attribute } & \multicolumn{2}{|c|}{ Gender } & \multirow{2}{*}{ Total $(\mathrm{N}=123)$} \\
\hline & Male $(\mathrm{N}=57)$ & Female $(\mathrm{N}=66)$ & \\
\hline \multicolumn{4}{|l|}{ Price (Baht per day) } \\
\hline 100 Baht & 0.17 & 0.22 & 0.20 \\
\hline 150 Baht & 0.09 & 0.05 & 0.07 \\
\hline 200 Baht & 0.16 & 0.15 & 0.15 \\
\hline Within Att. chi-square & 8.88 & 40.87 & 43.76 \\
\hline D.F. & 2.00 & 2.00 & 2.00 \\
\hline Significance & $\mathrm{p}<0.05$ & $\mathrm{p}<0.01$ & $\mathrm{p}<0.01$ \\
\hline \multicolumn{4}{|l|}{ Gender of the elderly carer } \\
\hline Male & 0.10 & 0.04 & 0.07 \\
\hline Female & 0.19 & 0.25 & 0.22 \\
\hline Within att. chi-square & 13.78 & 87.55 & 87.98 \\
\hline D.F. & 1.00 & 1.00 & 1.00 \\
\hline Significance & $\mathrm{p}<0.01$ & $\mathrm{p}<0.01$ & $\mathrm{p}<0.01$ \\
\hline \multicolumn{4}{|l|}{ Age of the elderly carer } \\
\hline 20-29 years old & 0.12 & 0.14 & 0.13 \\
\hline $30-39$ years old & 0.18 & 0.17 & 0.17 \\
\hline More than 40 years old & 0.15 & 0.12 & 0.13 \\
\hline Within att. chi-square & 3.48 & 2.42 & 4.42 \\
\hline D.F. & 2.00 & 2.00 & 2.00 \\
\hline Significance & not sig & not sig & not sig \\
\hline \multicolumn{4}{|l|}{ Working date of the elderly carer } \\
\hline Monday-Sunday & 0.13 & 0.09 & 0.11 \\
\hline Monday-Friday & 0.20 & 0.13 & 0.16 \\
\hline Saturday-Sunday & 0.08 & 0.16 & 0.13 \\
\hline Date and time flexible to the appointment & 0.18 & 0.22 & 0.20 \\
\hline Within att. chi-square & 12.76 & 18.99 & 19.56 \\
\hline D.F. & 3 & 3 & 3 \\
\hline Significance & $\mathrm{p}<0.01$ & $\mathrm{p}<0.01$ & $\mathrm{p}<0.01$ \\
\hline \multicolumn{4}{|l|}{ Characteristics of work } \\
\hline The elderly carer work at home and live with the elder & 0.10 & 0.09 & 0.09 \\
\hline $\begin{array}{l}\text { The elderly carer come to work in the morning and go } \\
\text { back in the afternoon }\end{array}$ & 0.20 & 0.21 & 0.21 \\
\hline Within att. chi-square & 19.59 & 31.64 & 50.89 \\
\hline D.F. & 1.00 & 1.00 & 1.00 \\
\hline Significance & $\mathrm{p}<0.01$ & $\mathrm{p}<0.01$ & $\mathrm{p}<0.01$ \\
\hline
\end{tabular}

Data source: the authors' calculation. 
The results of multinomial logic estimation of average utility values for the elderly care attributes classified by gender are applied to present in graph. For interpreting the results, it is helpful to plot the utility functions. The utility function values for each attribute are graphed in Fig. 2-Fig. 6. As it can be seen from Fig. 2, the respondents have the greatest preference for a 100 Baht price of the elderly care. Men have more preference on the higher price at 200 Baht. However, for the 100 Baht price, women have higher preference than men. The price of 150 Baht is least preferred in both groups.

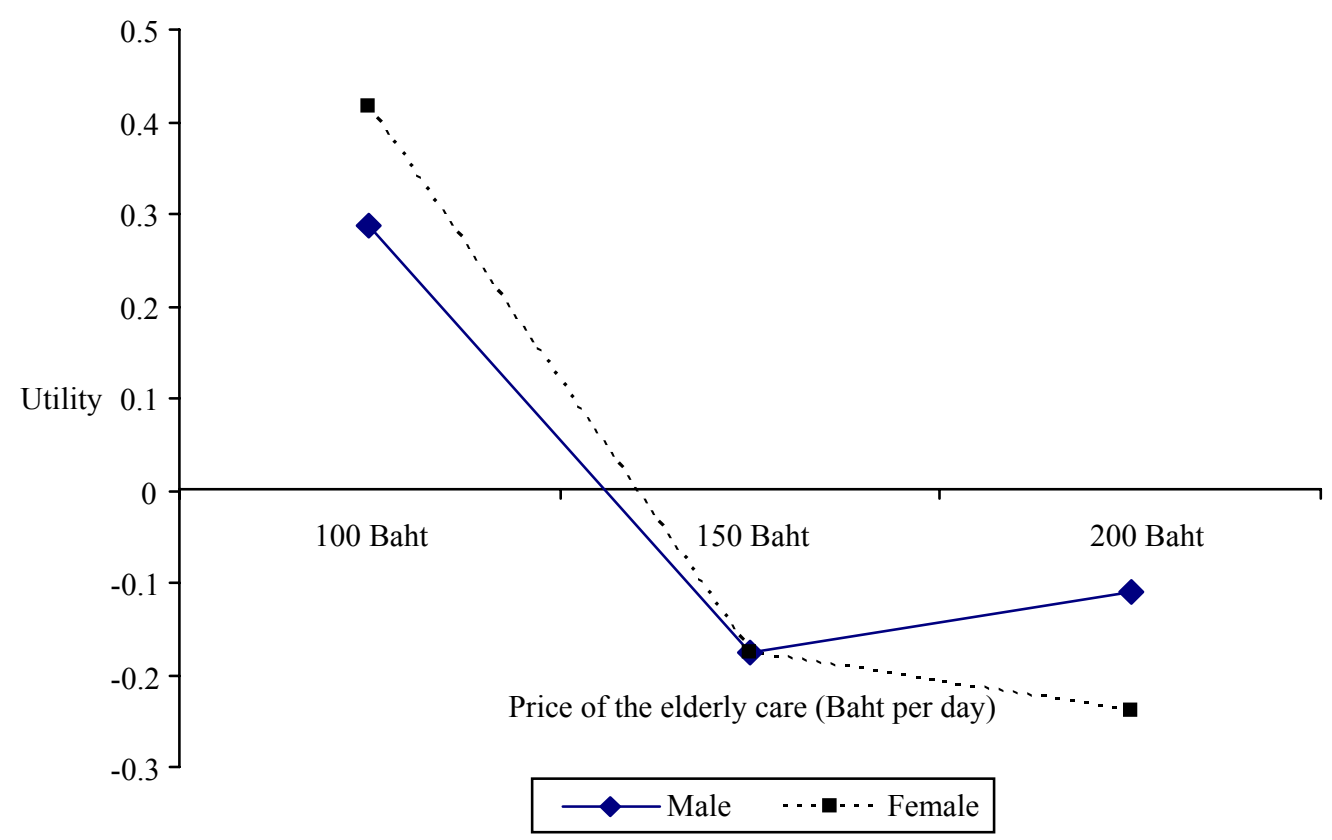

Fig. 2 Relationship of utility and price of the elderly care

Data source: the authors' calculation.

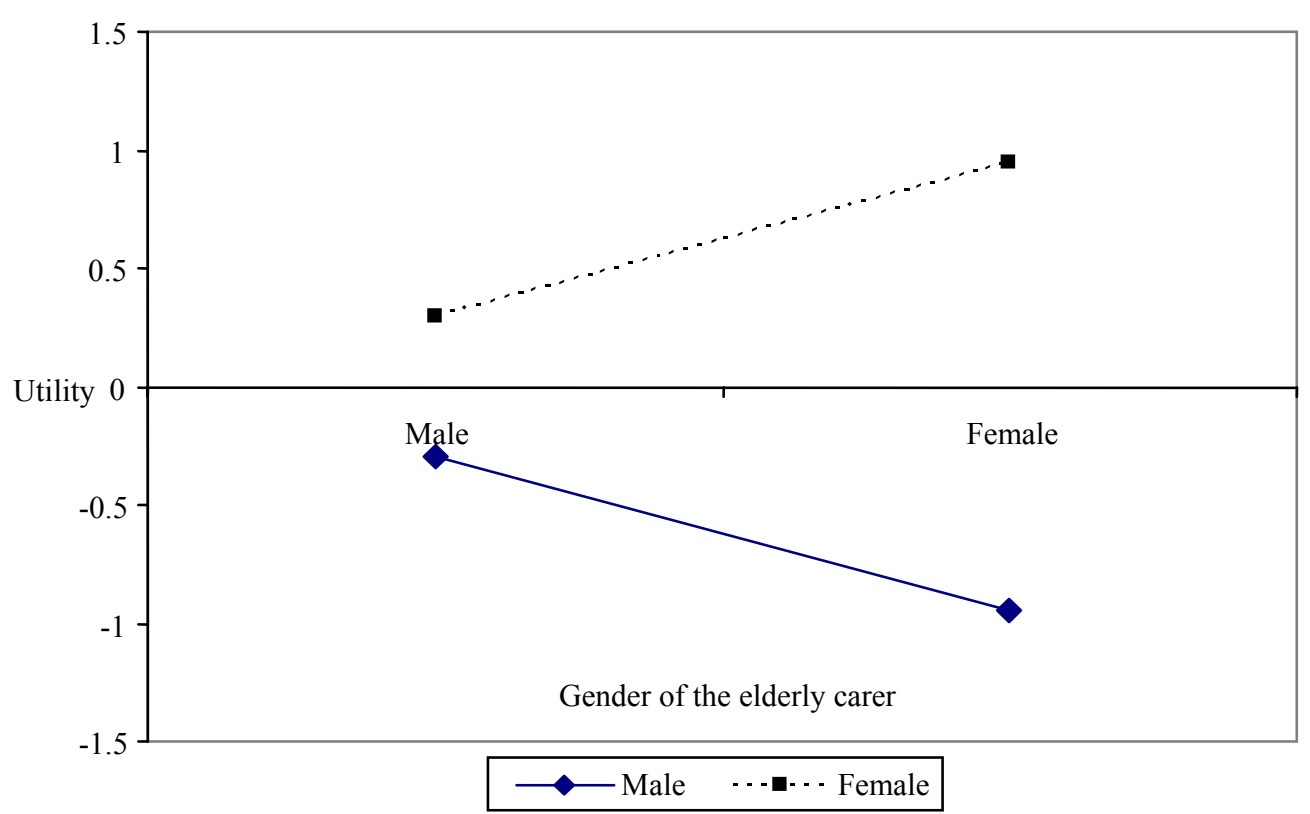

Fig. 3 Relationship of utility and gender of the elderly carer

Data source: the authors' calculation. 
Fig. 3 shows the relationship of utility and gender of the elderly carer. Female elders have higher utility on hiring female elderly care than male elderly carer. On the other hand, male elders have lower utility on hiring female elderly carer. This might because the elderly carers who have the same genders as the elders can understand and work easily with them.

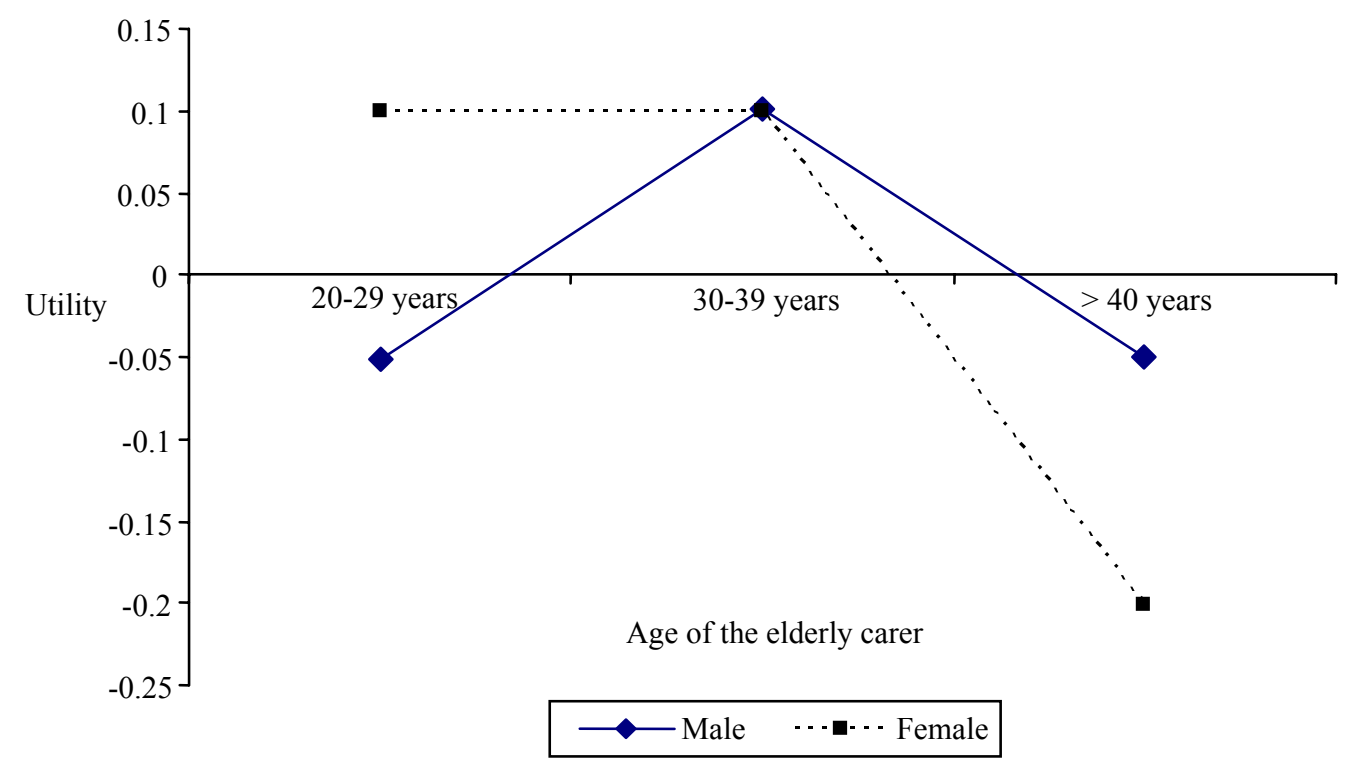

Fig. 4 Relationship of utility and age of the elderly carer

Data source: the authors' calculation.

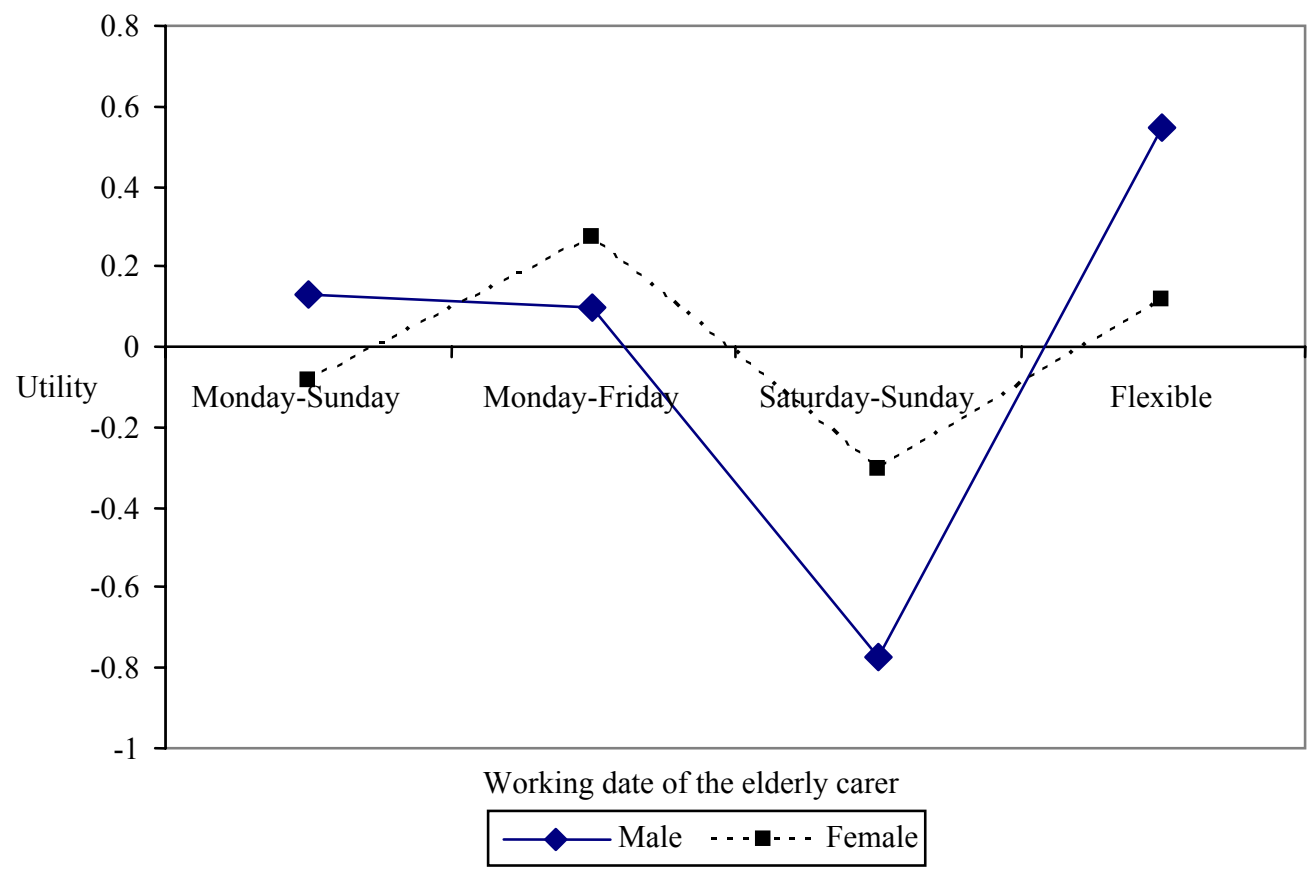

Fig. 5 Relationship of utility and working date of the elderly carer

Data source: the authors' calculation.

The importance of the age of the elderly care is presented in Fig. 4. The "age of the elderly carer between 
30-39 years old" attribute level is most preferred for both sexes. This implies that they do like the middle age people who have experience to take care of them. Female elders have high utility on hiring the elderly carer age between 20-29 years old more than male elders, while male elders have high utility on hiring the elderly carer age more than 40 years old.

According to the working date of the elderly care attribute, female elders have the tendency to hire the elderly carer to work on Monday to Friday and Saturday to Sunday more than male elders. Working date and time flexible to the appointment is most popular in both group of the elders (see Fig. 5).

As may be expected, the relationship between utility and the characteristics of the elderly care working is consistent in both groups. The elders prefer to the elderly carers come to work in the morning and go back in the afternoon (see Fig. 6).

Result from group discussion with the elder gives an interesting result that the elderly welfare arrangement nowadays is better than the past. There is the law on the elderly to protect the elders, but there are still some problems must be improved. In brief, the elders complain that it is not cope with all elders and the welfare arrangement is still not cover all the lists that have been written in the act. The elder welfare program has been run under the limitation of budget. The service is so slow. The welfare arrangement covers only some group of the elder who have close relationship with the officer's friends or relatives.

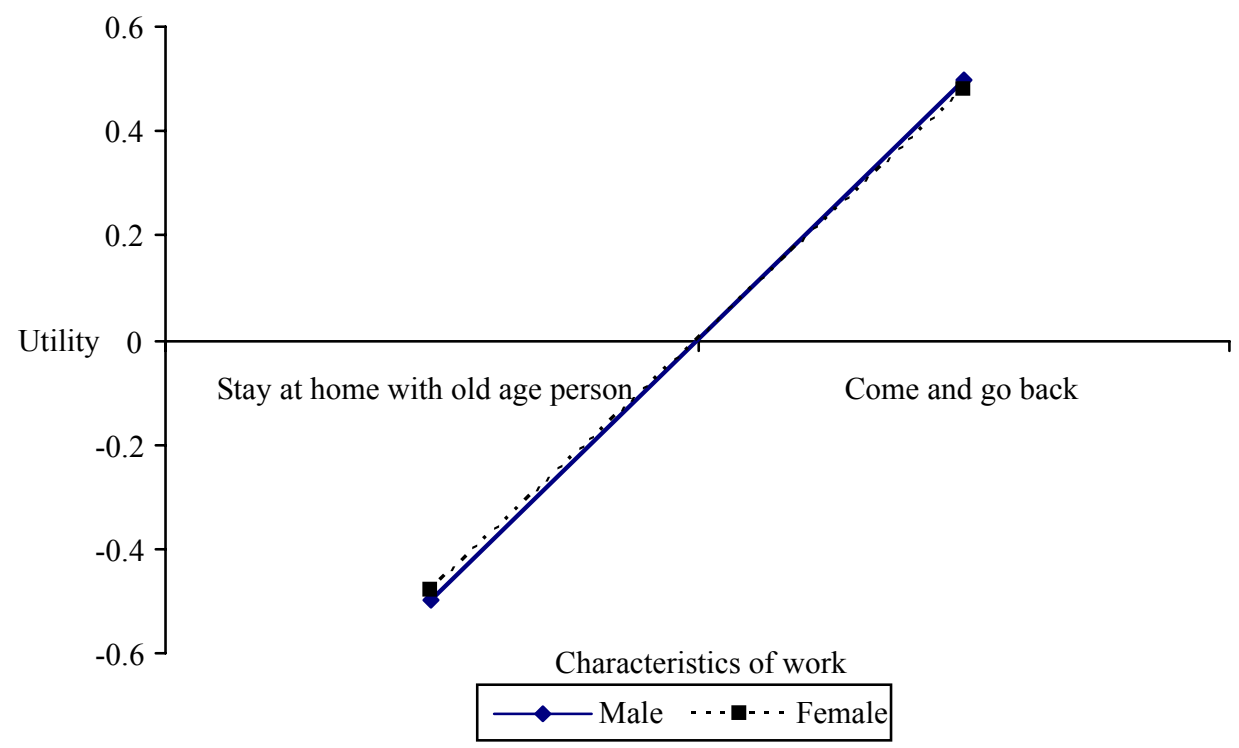

Fig. 6 Relationship of utility and characteristics of the elderly carer's work

Data source: the authors' calculation.

\section{Conclusions and recommendations}

In conclusion, most elders hope to the related organization to improve present elder welfare arrangement. Money support should be distributed in the efficient and fair way. Money support should readjust to the living cost. The moral of the officer is very important. In fact, many elders do not get aids and the elder welfare is still not cover basic needs. It is no matter about the pattern of new welfare arrangement, the most important point to recognize is the inspection and evaluation of the outcome - whether the elder get the aids or not. Therefore, the community committee should have the elder lists to recheck the result. Moreover, the elderly welfare arrangement 
should provide service directly to target group.

The suggestion on the elderly welfare arrangement can be concluded as follows:

(1) The elder card distribution: In some community, the elder must propose the documents to express the demand on card, and it spends long time to get the card; Some receive it when it is nearly to expire; Some elders can not access to welfare service. The service should be reached to everyone without requesting. Most of the elders have health problem, so it is difficult to travel to use the service. Moreover, the elder card should be as smart card, which can be used to discount for public transportation.

(2) Money supports: The elders who do not receive money supports display the opinion that the distribution of money should cover all elders, not only someone who have close relationship with the community leader and local politician. Government should pay attention on the neglected elderly group. The elder groups who receive money support express the idea that money supports should adjust to the present living cost. The aids should cover the welfare like the dental surgery. Some feel that they pay a lot on tax when they work, but the return after retirement age is so little. The elders who live in remote area want government support money to do the activities in community and support the community elderly fund. The elders who get the life pension monthly payment want the new form of life pension, which can be passed to their wife and sons.

(3) Sports and entertainments: Government should promote good health among the elder through sports, aerobic, music and entertainments activities.

(4) Medical care services: Medical care services should be free and have service reach to the elder. Many elders gain benefit from universal health care card, because it can reduce their health expenditure. Some elders need mental support and want somebody to talk with. So, the sociologists and psychologists should work together with the medical care staff to create the activities related to the elders.

(5) The elderly care center: The elderly care plays a significant role in the future since the society has been changed. The reliability on the help from descendants becomes more difficult because of the migration of teenager to work in other province. Thus, demand on the elderly care is high among the ripe and ill elders. Some are live alone without descendants and can not support the elderly care cost. It is the duty of government to support and share the cost. However, the skill, expert and sincere elderly care are rare. Hence, the elderly care training center is necessary. This center can help the elders who need on elderly care, and create job for the unemployed. The center should be settled in community and give the service to consult the elder.

(6) The training course for the elder: There should be the training courses about the preparation after retirement age, covering the physical and psychological preparation of changed.

(7) The elderly aids organization: Many elders think that there should be a public organization to work and follow up the elders, especially some who live alone in remote area. This organization should set activities and place for the elders to join together. Government should support some budget for this organization.

(8) Living place for the elder: The environment of elderly housing and living place should be improved to make the elder feel as at home.

(9) Job creation: There is the idea of creating the elder welfare with least cost by creating job for the elder and return in term of income for many elders who are retired but still have nice health and ability to work.

(10) The announcement of update information of elder welfare: Rural elders can access to the elder welfare less than urban elders. The arrangement of elder welfare should have the announcement of update information of elder welfare through many channels. Inside this booklet should show the schedule of activities, appointment, news and interesting information. 
(11) The integration of elder: The integration of elder both in formal and informal way can help them reach welfare easily. Hence, the elder association, in the formal way, acts as the intermediate tool to help the elder to get news and distribute the aids. The integration group of the elder in community, one of the informal ways, also is the social groups that should help them.

\section{References:}

Basilevsky, A. T.. (1994). Statistical factor analysis and related methods. New York: John Wiley and Sons.

Fotaki, M., et al. (2005, December). Patient choice and the organization and delivery of health services: Scoping review. Report for the National Co-ordinating Centre for NHS Service Delivery and Organisation R\&D (NCCSDO).

Malhotra, N. K.. (2004). Marketing research: An applied orientation. USA: Pearson/Prentice-Hall.

National Economics and Social Advisory Council. (2007). The estimation of Thailand population from 2000 to 2020. Retrieved April 2008, from http://www2.nesac.go.th/document/images06/06100012c.doc.

National of Thailand. (2002). Population statistics. Retrieved April 2008, from http://www.service.nso.go.th/nso/data/data23_old/ data23_1.html.

Poder, J. J., Barendregt, J. J. \& Hans, V. O.. (2006, October). Health care costs in the last year of life-The Dutch experience. Social Science and Medicine, 63(7), 1720-1731.

Sricharoen, T.. (2007). Vulnerability and risk management for sustainable livelihoods of farm households in Northern Thailand: The role of health insurance in managing risks. (Doctoral dissertation, Stuttgart, Germany: University of Hohenheim)

(Edited by Ruby and Chris)

\section{(continued from Page 36)}

McMillen, D. P.. (1996). One hundred and fifty years of land values in Chicago: A nonparametric approach. Journal of Urban Economics, 40, 100-124.

McMillen, D. P. \& McDonald, J. F.. (1991). A simultaneous equations model of zoning and land values. Regional Science and Urban Economics, 21, 55-71.

Mulligan, G. F., Franklin, R. \& Esparza, A. X.. (2002). Housing prices in Tucson, Arizona. Urban Geography, 23(5), 446-470.

Openshaw, S.. (1984). The modifiable areal unit problem: Concepts and techniques in modern geography. Norwich: Geo Books.

Palmquist, R. B.. (1984). Estimating the demand for the characteristics of housing. Review of Economics and Statistics, 66, $394-404$.

Peiser, R. B.. (1987). The determinants of non-residential urban land values. Journal of Urban Economics, 22, 340-360.

Shukla, V. \& Waddell, P.. (1991). Finn location and land use in discrete urban space: A study of the spatial structure of Dallas-Fort worth. Regional Science and Urban Economics, 21, 225-253.

Wen, H. Z.. (2004). Hedonic price of urban housing: Theoretical and empirical research. (Doctoral dissertation, Zhejiang University) (in Chinese). 